\title{
LETRAMENTOS NA UATI: EXPERIÊNCIAS DE ESCRITA COM OS IDOSOS
}

\author{
Iva Autina Cavalcante Lima ${ }^{1}$ \\ Waltenice David de Sena Carvalho ${ }^{2}$
}

\begin{abstract}
RESUMO
Este trabalho relata sobre experiências de escrita de participantes da UATI (Universidade Aberta à Terceira Idade) durante as oficinas de rádio e canto, com a proposição de encontrar indícios de letramentos de uso cotidiano entre os processos de escrita vivenciados por estes quando das suas atividades realizadas durante as oficinas. As oficinas citadas foram organizadas e realizadas pelos professores voluntários na UATI do DCH III, campus de Juazeiro da Universidade do Estado da Bahia, no período da investigação. A partir da observação participativa, entrevistas semiestruturadas com duas participantes da UATI, e posterior análise dos dados, advindos das experiências de letramentos observadas, os participantes envolvidos relataram que encontraram muitos estímulos para a memorização, a aprendizagem contínua, satisfação no seu estar e junto aos seus pares e familiares, além de sentir-se ativo nos momentos de debilidades na saúde. Para realização desta pesquisa contou-se com as contribuições dos autores como Olson (1997), Street (2014) e Kleiman (2014), que trazem, respectivamente, uma discussão sobre as implicações da leitura e da escrita e sobre o letramento, enquanto interculturalidade e prática social.
\end{abstract}

Palavras-chave: Letramento. Escrita. Idoso.

\section{LITERACY AT UATI: WRITING EXPERIENCES WITH THE ELDERLY (MAIÚSCULAS, NEGRITO, FONTE TIME NEW ROMAN, 12; centralizado; espaçamento simples)}

\begin{abstract}
:
This paper reports on the writing experiences of UATI (Open University for the Elderly) participants during radio and singing workshops, with the purpose of finding evidence of literacy in everyday use among the writing processes experienced by them during their activities carried out during the workshops. The aforementioned workshops were organized and carried out by volunteer professors at the UATI of DCH III, campus of Juazeiro-BA, during the period of investigation. From participatory observation, semi-structured interviews with two UATI participants, and subsequent data analysis, arising from observed literacy experiences, the participants involved reported that they found many stimuli for memorization, continuous learning, satisfaction in their being and with the peers and family members, in addition to feeling active in times of health weakness. To carry out this research, we relied on the contributions of authors such as Olson (1997), Street (2014) and Kleiman (2014), who respectively bring a discussion on the implications of reading and writing and on literacy as an interculturality. and social practice.
\end{abstract}

Keywords: Literacy. Writing. Elderly.

\footnotetext{
${ }^{1}$ Docente do Departamento de Ciências Humanas DCH-III. Email: iclima@uneb.br ${ }^{2}$ Idem.
} 


\section{Introdução}

Discutir sobre a população idosa nos remete a lembrar sobre o processo de envelhecimento, em que o corpo físico, psicológico e motor sofre alterações como a perda de memória e começa a diminuir o ritmo e suas habilidades, não respondendo mais satisfatoriamente aos comandos emitidos pelo cérebro com o mesmo potencial de quando era jovem, dentre outros aspectos. Neste sentido, pensar e planejar atividades que favoreçam um processo de envelhecimento com melhor qualidade de vida, tem se constituído em planos de ações estratégicas de políticas públicas.

Com esse entendimento e, considerando o aumento da população de idosos no mundo, com mais de 840 milhões de pessoas, em que subestima-se para 2025 a projeção de 30 milhões.pessoas na terceira idade, somente no Brasil, de acordo com o relatório World Health Statistics 2015, da Organização Mundial de Saúde (OMS), as ações em torno dessa população são extremamentes fundamentais. Atualmente no Brasil temos em torno de 20 milhões de pessoas acima de 60 anos.

É perceptível o crescimento, tanto nos grandes centros como em pequenos municípios, na demanda dessa população por atividades que favoreçam seu bem-estar físico, mental e de convívio social, visando uma melhor qualidade de vida durante o envelhecimento e, consequentemente, maior expectativa de vida. Uma das recomendações da OMS é que se faça urgente a integração dos idosos, cada vez mais, à vida moderna, com atividades que lhes favoreçam melhor bem estar.

Nessa perspectiva, nasceu a Universidade Aberta à Terceira Idade (UATI) na Universidade do Estado da Bahia, como um programa de extensão universitária que se caracteriza em uma proposta de educação continuada não formal, no qual atende a pessoas de ambos os sexos e de qualquer nível sócio educacional, cuja faixa etária seja igual ou superior a 60 anos, objetivando a reinserção psicossocial dessa população para a aprendizagem continuada e o pleno exercício da cidadania.

Neste sentido, a UATI tem desenvolvido ações educativas de caráter permanente, com o propósito de estimular e garantir a reflexão sobre as diversas concepções de velhice no cenário da contemporaneidade [1], sob a ótica da Pedagogia Social, como preconiza Caliman (2010), enquanto “[...] uma ciência sensível à 
dimensão da sociabilidade humana, ou seja, que se ocupa particularmente da educação social de indivíduos historicamente situados" (pág. 343).

No Departamento de Ciências Humanas - DCH, Campus III da UNEB, na cidade de Juazeiro-BA, o programa de extensão universitária UATI, vinculado ao Núcleo Universidade Aberta à Terceira Idade (NUATI), foi implantado em abril de 2009. Relativamente à formação da turma, um número de vagas é definido para que todos recebam assistência, no entanto os participantes matriculados podem continuar no programa enquanto tiverem interesses em participar no mesmo e, à medida que novas vagas são disponibilizadas, novos participantes são recebidos, não existindo, portanto, conclusão de turma, apenas a entrega de certificados, referente a cada ano, pois, de acordo com o Projeto Pedagógico da UATI, a educação é permanente.

Sendo assim, no que concerne às atividades realizadas na turma, geralmente os participantes anotam e registram todos os conteúdos e assuntos abordados no "caderno de classe". Também lidam com os textos escritos da forma como se encontram mais confortáveis, principalmente nas oficinas de rádio e canto. Além do caderno também utilizam o celular para envio e recebimento de mensagens por meio do aplicativo Whatsapp, ampliando assim suas capacidades de comunicação, apresentando sua relação com as diferentes tecnologias no mundo contemporâneo a ampliando seu letramento digital. Nesse sentido, para Kleiman (2014), “o processo de apropriação de uma tecnologia ou de algum outro recurso midiático — o acesso — depende das estratégias forjadas pelos próprios sujeitos para fazer uso do material”. E eles fizeram.

Dessa maneira, motivados pela ação da escrita nos variados recursos disponíveis dos/das alunos/as da UATI, no Departamento, o objetivo deste artigo é apresentar nossas percepções de letramento ocorridas nas atividades com os idosos a partir da experiência de escrita desenvolvida com uma turma de frequentadores da UATI no DCH III/UNEB. Portanto, pretende-se descrever, neste trabalho, algumas maneiras como eles/elas se apropriaram de letramentos múltiplos a partir das práticas de escrita vivenciadas. Com o intuito de ampliar as nossas percepções, faz-se necessário apresentar concepções referentes à escrita e letramento, perpassando pela sua história e por discussões diversas que subsidiam boa parte da base de estudos nesse campo. 


\section{Um olhar sobre a história da escrita e alguns conceitos de letramento(s)}

A escrita está presente em todo lugar, seja de maneira formal ou não. Por meio dela é possível formar uma opinião ou um posicionamento e ter acesso à ideia de outros. Com isso, percebe-se a sua importância, não apenas na comunicação/informação (até porque existem outras formas de informar sem que seja, necessariamente, por meio da escrita), mas também para registrar, para reduzir distâncias, para minimizar tempo e aproximar pessoas.

A escrita surge como uma função social e muitas das nossas relações constituem seus artefatos (OLSON, 1997), dando a entender que a escrita é a materialização do pensamento e, por sua vez, da linguagem; em que está ligada, também, à formação cognitiva do ser humano que, já na infância, passa a externalizar os primeiros significados do mundo ao seu redor, a partir das primeiras palavras. Esse desenvolvimento cognitivo é caracterizado pela capacidade de abstração ou descontextualização do conhecimento.

Partindo desse pressuposto e de acordo com Olson (1997), foi a partir de 1960 que os estudos sobre a escrita ganharam força na academia. Vários profissionais se juntaram aos estudiosos da pedagogia para se debruçar sobre esse tema, com o objetivo de entender sobre as suas implicações na vida das pessoas ao longo da história. Esse mesmo autor discorre sobre o pensamento primitivo, apresentando a noção de mente "primitiva", para se referir a um pensamento privado dos benefícios da cultura e para mostrar o modo de pensar de diversos povos primitivos, que se apropriaram de alguns objetos para representar contextos da sua vivência.

Ainda sobre a escrita, Olson (1997, pg. 38) afirma que esse fenômeno "é, naturalmente, uma realização histórica". Porém, o mesmo não acontece com a racionalidade, muito embora esta seja fundamental para que a aquisição da escrita seja efetivada. Entende-se com isso que a escrita tem total relação com a escolaridade, pois de acordo com o mesmo autor, não se pode separar o domínio da linguagem escrita da escolaridade e da ação de alfabetizar; alfabetizar, todavia, é mais do que aprender o alfabeto; é também aprender a utilizar os recursos da escrita num conjunto de tarefas e procedimentos estabelecidos por esse método. 
Salienta-se que, não é apenas na escola que a escrita é percebida, mas a partir dela, pois ao se perceber o domínio dessa linguagem pelos indivíduos em qualquer espaço da sociedade, pode-se identificar processos de letramentos, o que torna os indivíduos capazes de responderem às demandas do seu contexto social e, portanto, mais ativos. Com isso, faz-se necessário compreender como acontecem esses processos e o sentido dos mesmos nos diversos setores das sociedade, especialmente para os sujeitos que a compõem.

As concepções de letramento não são unânimes. Uma compreensão inicial que se tem de letramento é aquela que está ligada também à escolarização, ou seja, uma pessoa que frequentou a escola, foi alfabetizada, aprendeu a ler e a escrever, pode ser considerada "letrada". No entanto, um novo sentido vem sendo dado ao letramento, em que se apresenta além da leitura e da escrita e dos muros da escola, assumindo um aspecto de interculturalidade em que Street (2014) apregoa ser mais abrangente que a leitura e a escrita e que não existe um único tipo de letramento.

Street critica também o estigma do "analfabetismo", indo de encontro aos programas de alfabetização que têm objetivos apenas de alcançar os analfabetos, desconsiderando o saber intrínseco das pessoas, bem como os letramentos locais, oriundos de sua própria cultura. Nesse sentido, percebe-se nos participantes da UATI que, por apresentarem diferentes habilidades nas oficinas ofertadas, revelam os saberes diversos que lhes conferem suas apropriações na vida cotidiana.

$\mathrm{Na}$ sua obra "Letramentos Sociais", Street (2014) afirma que as agências de alfabetização fomentam o que ele chama de modelo "autônomo" de letramento, cuja preocupação está em ensinar as pessoas a decodificar sinais escritos para evitar problemas de ortografia, questões essas, consideradas pelo autor, de aparentemente técnicas. Para o autor, antes de tais questões, há outras a serem enfrentadas, que são aquelas derivadas de um modelo alternativo de letramento, ou seja, o modelo "ideológico". Assim, entende-se que o letramento acontece ou se modifica de acordo com a cultura de determinadas sociedades, sendo trabalhado, preferencialmente, num modelo ideológico, pelos seus múltiplos significados, por estarem relacionados a contextos específicos e porque algumas práticas estão associadas à relações de poder e ideologia. Nessa compreensão, pode-se afirmar que em boa parte das atividades 
humanas existem práticas de letramento, desde às relações familiares, aos ambientes de trabalho, religiosos e até de lazer e entretenimento. Dessa forma, qualquer atividade desenvolvida por uma pessoa, onde há a presença da escrita, pode se tratar de um evento de letramento. Esse modelo é incorporado pelas práticas sociais que, de acordo com (STREET, 2014, p. 18), as práticas estão "num nível mais alto de abstração e se refere igualmente ao comportamento e às contextualizações sociais e culturais que conferem sentido aos usos da leitura e/ou da escrita”. Essas práticas estão relacionadas ao modelo ideológico de letramento, conforme traduz Street (2014, p. 44):

O modelo ressalta a importância do processo de socialização na construção do significado do letramento para os participantes e, portanto, se preocupa com as instituições sociais gerais por meio das quais esse processo se dá, e não somente com as instituições 'pedagógicas'.

É nessa sua visão que Street (2014) concebe que as práticas de letramento são constituintes de identidade e pessoalidade, associadas às perspectivas sociais acerca de modelos de comportamentos. Como exemplo disso, o autor ressalta na sua obra atitudes de mulheres que, para saírem das obrigações domésticas, buscam se capacitar em diversas atividades a fim de assumirem uma nova profissão. $\mathrm{O}$ autor sugere, ainda, que os modos de pessoalidade e letramento estão interligados em diversos discursos culturais, servindo para nos lembrar que, para a aquisição de letramentos, envolvem-se habilidades que vão além de técnicas.

Partindo desse pressuposto, o projeto da UATI se constitui como uma prática social em que se encontram diferentes práticas e eventos de letramentos. Primeiro, por se tratar de um lugar onde é acolhido um determinado público, no caso os idosos, a fim de desenvolverem ações de interesses e necessidades dos mesmos, como forma de promover a inclusão, e, para além disso, satisfação pessoal e qualidade de vida, dentre outras possibilidades. Segundo, porque em boa parte das atividades desenvolvidas com e para esse público, há a presença da escrita e de múltiplos letramentos. Portanto, buscaremos apresentar, a seguir, as atividades que nos fizerem observar as práticas e eventos de letramento com os participantes da UATI.

\section{Experiências de letramento(s) na UATI}


As atividades da Universidade Aberta à Terceira Idade (UATI) aconteciam por meio de oficinas realizadas no Departamento de Ciências Humanas (DCH/Campus III), com a participação de um instrutor/monitor para cada uma delas. No DCH III as oficinas eram realizadas diariamente, ou seja, de segunda a sexta-feira e, em cada dia da semana, funcionava uma oficina diferente, a saber: rádio, desenho e pintura, canto coral, informática e artesanato. Dentre essas, as oficinas de canto e de rádio foram as que mais se destacaram nas atividades ligadas diretamente com a leitura e escrita, portanto, alvo maior das observações neste trabalho.

Nas oficinas de canto, os participantes realizavam os ensaios com as cópias das letras das músicas, entregues e sugeridas pelo próprio instrutor (que também organizava a divisão de vozes). As músicas eram reproduzidas no ambiente (melodia e letra) e acompanhadas pela turma. Todos os participantes em seus postos formavam um coral que se apresentava em datas oportunas nos eventos do próprio departamento (DCH III), a exemplo das festas juninas e época do Natal.

Já na oficina de rádio, as atividades que se destacaram foram: 1) a visita à uma emissora de rádio, onde puderam conhecer a história do rádio, a linguagem radiofônica e formatos radiofônicos, ajudando-as a relembrarem de suas experiências com esse veículo de comunicação; e 2) criação de textos para a produção de um programa experimental de rádio. Boa parte destes textos foram elaborados a partir de suas histórias de vida, rememorando as músicas (letra e melodia) que marcaram alguma fase de suas vidas, como a mocidade, por exemplo. As buscas das letras e melodias musicais foram realizadas via Internet, levando-as a reviverem histórias e fatos experienciados, como os namoros, casamentos, nascimento de filhos e netos, entre outros.

Após a criação dos textos pelos participantes, a turma se reuniu para escolha de um nome e perfil do programa, além da escolha também de duas apresentadoras. Estas foram encaminhadas para o laboratório de rádio do próprio departamento, com prévio agendamento, para a gravação, utilizando um roteiro (script) para a leitura.

Enquanto evento de letramento, fenômeno mencionado pelos teóricos citados no tópico anterior neste trabalho, essa atividade de rádio não apenas contribuiu com o processo de rememoração dos idosos, mas também despertou outras habilidades, como cantar e dançar, habilidades ora adormecidas, conforme citou uma das participantes 
entrevistadas. Foi possível, com a referida atividade, perceber a memória sendo amplamente ativada, fator indispensável para a manutenção da saúde mental, especialmente na idade em que essa população se encontra.

No decorrer da pesquisa, buscou-se acompanhar na prática o processo e o significado do letramento aqui concebidos, onde foram observadas mais claramente por duas (02) participantes em suas atividades. Além disso, foram realizadas entrevistas com as mesmas, a fim de conhecer mais sobre suas histórias de vida e como a escrita estava presente no seu cotidiano. Para preservar suas identidades, foram atribuídos os pseudônimos "Rosa" e "Flor" para as mesmas. Rosa, uma professora aposentada de 68 anos de idade e Flor, de 87 anos, não exerceu nenhuma profissão fora de casa e, por isso, como ela mesma declarou, era considerada "do lar" ou doméstica (como anteriormente se denominava).

Inicialmente, ambas buscaram a UATI por haver se identificado com o programa, o que as possibilitou perceber um sentimento prazeroso ao fazerem parte do mesmo. Através deste programa, suas tardes deram um salto qualitativo e passaram a ter muito mais significado, principalmente por tirá-las da ociosidade, de acordo com as participantes entrevistadas. Sobre isso, Rosa foi mais além e declarou que buscou a UATI para lhe completar em algo que lhe faltava e lhe oferecer ocupação no tempo ocioso.

O que pudemos observar, a partir das respostas, foi a necessidade de outras realizações pessoais e de desenvolver outras atividades que não puderam realizar enquanto mais jovem, além de preencher o tempo com atividades que oferecessem prazer e contentamento. No caso de Flor, o propósito foi outro bem diferente: a UATI foi apresentada à mesma enquanto enfrentava um problema de saúde. Problema esse surgido após o falecimento de seu esposo, o que a deixou bastante fragilizada. Segundo Flor, "A UATI foi uma bênção divina! Um milagre!" Flor declarou, ainda, que teve oportunidade de fazer novos amigos, além de obter mais diversão, minimizando a dor causada pelo luto, vindo a melhorar significativamente o seu estado de humor e saúde após a sua participação no programa. Com essas declarações, percebe-se os modos distintos como essas participantes conheceram a UATI, destacando as suas satisfações 
em participar desse programa, fator estimulante para a frequência com regularidade e, ainda, confirmando os estudos sobre a reinserção dos idosos no meio social.

Rosa, antes de tornar-se aluna do programa, foi procurada pela coordenação da UATI para desenvolver uma oficina de Língua Brasileira de Sinais (Libras), devido a suas experiências anteriores como docente em uma escola de surdos. O intuito do convite era somente para suprir a ausência de monitor, mas por motivo da falta de instrutores as vagas ainda permanecerem abertas no início do semestre e Rosa foi convidada para assumir efetivamente a vaga, passando a dar orientações básicas sobre LIBRAS, oportunizando aos demais participantes a obterem uma noção sobre essa língua; e, ainda, levando-os a perceberem o sentido de se comunicar através dos gestos, contribuindo para mostrar aos participantes outras possibilidades de comunicação, além da escrita. Para Rosa, desenvolver tal atividade foi uma oportunidade singular, porque a fez relembrar aspectos ligados à cognição, além de ser útil para outras pessoas, especialmente os colegas da sua faixa etária de idade.

Passada essa experiência, no ano seguinte, após tomar conhecimento das oficinas e, devido a necessidade de se ocupar-se com outras atividades para sair da ociosidade, Rosa ingressou no programa, dessa vez como aluna. Para ela, a oportunidade de atuar nessa outra categoria foi importante também, principalmente, pelas novas experiências adquiridas e por poder aprimorar outras que julgava ter dificuldades. Na sua fala, Rosa citou um dos benefícios alcançados por meio da UATI, que foi participar do coral. Segundo ela, uma "atividade que traz benefício mental e, [além disso], prazerosa".

Outra oficina bastante importante para Rosa foi a de rádio, pelas lembranças afetivas proporcionadas pela mesma. Para ela, foi uma das atividades mais significativas, pois trouxe muitas lembranças importantes, como por exemplo, a relação que tinha com seu pai, bem como a relação que ambos tinham com o rádio, quando tiveram oportunidade de participarem de programas de rádio ao vivo. Já para Flor, a experiência que mais marcou nessa oficina foi lembrar o passado, adolescência, namorados, casamento, filhos. Declarou a mesma que “... isso é muito bom! Recordar é viver". Essa atividade foi muito interessante para a mesma. 
Com os depoimentos apresentados pelas participantes, pode-se perceber a importância de programas como a Universidade Aberta à Terceira Idade (UATI). É comum ver pessoas dizerem que, ao se aposentarem, "vão cruzar os braços"; outras dizem que vão passear muito ou realizar algo que não conseguiram enquanto estavam empregados ou exercendo atividades profissionais. Mas o fato é que, tais pessoas se aposentam, algumas já com sessenta anos ou mais e se esquecem que, junto com essa fase da vida, vêm os problemas ligados à saúde; a mente e o corpo já não respondem com a mesma habilidade de quando eram mais jovens. Daí a necessidade de haver mais estimuladores (família e profissionais que estudam a terceira idade) para que os idosos não se tornem ociosos e continuem sempre ativos, buscando realizar coisas que lhe dão prazer e aprendam continuamente.

Assim, a leitura e a escrita estimuladas através das citadas oficinas favorecem na manutenção da saúde mental, ou seja, de uma boa memória, e, consequentemente, possibilitando novos conhecimentos. Sabendo-se que ler e escrever são atividades que contribuem na manutenção ativa da mente e a assimilar novos conhecimentos e, dentre outros benefícios, ajuda a reduzir os riscos de síndromes como Alzheimer.

Ainda no que diz respeito à prática da escrita, ambas participantes disseram que gostam muito de escrever e sempre dispõem de um caderno para suas anotações cotidianas Rosa, por exemplo, mantém sempre consigo um caderno onde anota tudo de forma sistemática: “Ao invés de tirar cópia, escrevo tudo no caderno", - disse ela ao se referir a apostila da oficina de rádio. Tanto para Rosa quanto para Flor, o caderno e a caneta nunca podem faltar nos encontros. A escrita também era praticada para se lembrarem das tarefas solicitadas em todas as oficinas e também para registros das atividades realizadas nas oficinas. Na UATI, o exercício da leitura e da escrita faz parte do cotidiano; sempre surge a necessidade de ler e anotar algo.

Por fim, um fato interessante que vale ressaltar, é que as redes sociais também estão presentes na vivência dos participantes. O aplicativo WhatsApp é muito usado nos bate-papos e comunicações diversas, seja por meio de áudio ou mensagens escritas. Tal fato demonstra que os idosos estão antenados e também podem interagir por meio das redes sociais, bastando para isso (em alguns casos) a disponibilidade de outras pessoas 
para ajudá-los no manuseio desses e outros aplicativos, algo que não falta no programa e nas oficinas de TIC, como exemplo..

\section{Considerações finais}

A escolha da UATI para esta observação foi necessária para compreender como acontecem os processos de aprendizado, da leitura e da escrita entre os idosos, podendo ser compreendido como um evento de letramento, pela forma como esse processo atua no desenvolvimento psicossocial desses indivíduos. Além disso, essa experiência foi essencial para compreensão da realidade desta população, mais especificamente, às suas práticas de letramento através dos eventos vivenciados.

Os resultados também mostraram que projetos como a UATI são imprescindíveis no atendimento à população idosa, em particular, com atividades que lhes permitam proporcionar maior qualidade de vida e, assim, possam responder aos estímulos provocados pela sociedade, a exemplo do avanço contínuo das tecnologias, passando a atuar de forma satisfatória entre os seus, sem deixar de considerar as limitações impostas pela idade.

A pesquisa mostrou que, mesmo com as limitações ocasionadas pela idade, o idoso pode desenvolver novas aprendizagens. Esse indivíduo ainda é um sujeito em potencial, pois além das suas experiências de vida que, por sinal, são bastantes valiosas, pode muito contribuir para a sociedade e, ainda, se sentir ativo na busca de novos conhecimentos e novas habilidades. O tempo dispensado pelos professores, voluntários ou pesquisadores para esse tipo de atividade na UATI é de fundamental importância para que a população idosa vivencie momentos diversos, como nessa experiência específica, de aprendizado, de superação, de elevação da autoestima e negação do ócio, entre outros fatores que possam contribuir com a qualidade de vida dessa população.

\section{REFERÊNCIAS BIBLIOGRÁFICAS}

BRASIL. Lei no 10.741, de $1^{\circ}$ de outubro de 2003._Dispõe sobre o Estatuto do Idoso e dá outras providências. Diário Oficial da União, Brasília, DF, 3 de out. 2003. 
Disponível em: <http://www.planalto.gov.br/ccivil_03/leis/2003/L10.741.htm>. Acesso em: 28 de jun. de 2021.

KLEIMAN, Angela B. (2014). Letramento na contemporaneidade. Bakhtiniana, São Paulo, 9 (2): 72-91, Ago./Dez. 2014.

LÓPEZ, Graciela L. O método etnográfico como um paradigma científico e sua aplicação na pesquisa. Universidade Luterana do Brasil. Doutorado em Saúde Pública da UBRA: 1999.

MATTOS, C. L. G.; CASTRO, P. A. (Orgs) A abordagem etnográfica na investigação científica. In: Etnografia e educação: conceitos e usos. Campina Grande: EDUEPB, 2011.

OLSON, David R. Teorias da escrita e da mente: de Levi-Bruhl a Scribner e Cole. In: OLSON, David R. O mundo no papel: as implicações conceituais e cognitivas da leitura e da escrita. Trad. Sergio Bath. São Paulo: Ática, 1997. Cap. 2, p. 37-60.

STREET, Brian V. Perspectivas interculturais sobre letramento. Trad.

Marcos Bagno. Revista de Filologia e Linguistica Portuguesa da Universidade de São Paulo. N.8. p. 465-488, 2007.

STREET, Brian V. Letramento sociais: abordagens críticas do letramento do desenvolvimento, na etnografia e na educação. Trad. Marcos Bagno. São Paulo: Parábola Editora, 2014.

UAUCANCE. Leitura estimula o cérebro dos idosos. Publicação de 21 de novembro de 2016. Disponível em: <http://www.uaucance.com.br/leitura-estimula-o-cerebro-dosidosos/> Acesso em 28 de jun. de 2021.

[1] Disponível em: http://www.nuati.uneb.br/saiba\%20mais.html. Acesso em: 28 jun. de 2021. 